NOTE

\title{
Reexamination of McQuarrie's Solution on the Kinetic Theory of Polymer-Analogous Reaction
}

\author{
Minoru UEDA \\ Central Research Laboratories, Kuraray Co., Ltd., \\ 2045-1 Sakazu, Kurashiki, Okayama 710, Japan.
}

\author{
KEY WORDS Polymer-Analogous \\ McQuarrie's Solution /
}

\author{
(Received May 6, 1980)
}

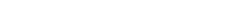




$$
\begin{aligned}
q_{1}= & \exp \left(-k_{2} t\right)\left[2\left(k_{2}-k_{1}\right) \mathrm{e}^{2\left(k_{1}-k_{0}\right) / k_{0}}\right. \\
& \times \int \mathrm{e}^{\left(k_{2}-2 k_{1}\right) t} \exp \left(A \mathrm{e}^{-k_{0} t}\right) \mathrm{d} t \\
+ & \left(2 k_{1}-k_{0}-k_{2}\right) \mathrm{e}^{2\left(k_{1}-k_{0}\right) / k_{0}} \int \mathrm{e}^{\left(k_{2}-k_{0}-2 k_{1}\right) t} \\
& \left.\times \exp \left(A \mathrm{e}^{-k_{0} t}\right) \mathrm{d} t+C\right]
\end{aligned}
$$

where $C$ is the intergration constant and $A=$ $2\left(k_{0}-k_{1}\right) / k_{0}$. Equation 6 is the function examined below.

Now our problem is to obtain an expression for $q_{1}$ other than eq 6 by using eq $1-5$. To make the final expression as compact as possible, let us change the variable $(t)$ by $s=\exp \left(-k_{0} t\right)$ and let $\alpha=k_{1} / k_{0}$, and $\beta=k_{2} / k_{0}$. Then, eq 5 can be expressed in a simpler form as follows,

$$
q_{j}=s^{j+2 \alpha-2} \exp [2(\alpha-1)(1-s)]
$$

From eq 1 and 2 with $j=1$ and eq 6 , we get,

$$
\begin{aligned}
q_{1}-p_{1} & =2 q_{2}-q_{3}=\sum_{i=2}^{N} i p_{i} \\
& =(2-s) s^{2 \alpha} \exp [2(\alpha-1)(1-s)]
\end{aligned}
$$

This is applicable for $j \geqq 2$.

By differentiating eq 2 with respect to $t$ at $j=1$, we obtain

$$
\mathrm{d} p_{1} / \mathrm{d} t=\mathrm{d} q_{1} / \mathrm{d} t-2 \mathrm{~d} q_{2} / \mathrm{d} t+\mathrm{d} q_{3} / \mathrm{d} t
$$

With the help of eq 1,3 , and 4 , eq 9 can be transformed as follows.

$$
\begin{aligned}
\mathrm{d} p_{1} / \mathrm{d} t= & 2 k_{0}\left(q_{3}-q_{4}\right)+2 k_{1}\left(q_{2}-2 q_{3}+q_{4}\right) \\
& +k_{2}\left(q_{1}-2 q_{2}+q_{3}\right)=2 k_{0} \sum_{i=3}^{N} p_{i} \\
& +2 k_{1} p_{2}-k_{2} p_{1}
\end{aligned}
$$

This differential equation is identical to that derived by Boucher for the isolated unreacted units. Thus, eq 10 leads to,

$$
\begin{gathered}
p_{1}=2 s^{\beta} \int_{s}^{1}(1-x)[\alpha(1-x)+x]^{2 \alpha-\beta-1} \\
\quad \times \exp [2(\alpha-1)(1-x)] \mathrm{d} x
\end{gathered}
$$

Equation 7 plus eq 11 given the result we sought and is identical with the equation given by Boucher ${ }^{4}$ and others. $^{6,7}$

The properties of eq 11 is still cannot be examined as well as those of eq 8 , however. For this to be possible, eq 11 must be modified by partial integration as follows,

$$
\begin{aligned}
p_{1}= & (1-s)^{2} s^{2 \alpha-1} \exp [2(\alpha-1)(1-s)] \\
+ & (2 \alpha-\beta-1) s^{\beta} \int_{s}^{1} x^{2 \alpha-\beta-2}(1-x)^{2} \\
& \quad \times \exp [2(\alpha-1)(1-x)] \mathrm{d} x
\end{aligned}
$$

It is certainly at once evident that the second term of the right-hand side of eq 12 becomes zero at $\beta=2 \alpha-1$. Under this condition, it can be shown that the resulting binary copolymer satisfies the conditions required for the Markov chain of the first-order. ${ }^{8}$ Hence the integral term in eq 12 represents the extent of deviation from the Markov chain of the first-order. Since eq 12 is the solution for the isolated unreacted units, the deviation is limited to these special unreacted units. This unique property of $q_{1}$ cannot be obtained from eq 6 unless transformed to eq 11 or 12 .

It is concluded that eq 8 plus 11 (or 12) is superior to the equation derived by McQuarrie, i.e., eq 6.

\section{REFERENCES}

1. N. A. Platé and O. V. Noah, Adv. Polym. Sci., 31, 133 (1979).

2. D. A. McQuarrie, J. P. McTague, and H. Reiss, Biopolymers, 3, 657 (1966); D. A. McQuarrie, J. Appl. Probl., 4, 413 (1967).

3. The term "polymer-analogous reaction" is the English translation of "polymerhomolog Umsetzungen" given by $\mathrm{H}$. Staudinger, K. Frey, and W. Starck, Ber., 60, 1782 (1927).

4. E. A. Boucher, J. Chem. Soc., Faraday Trans. 2, 68, 2295 (1972).

5. According to ref 1 , the mathematical justification of eq 5 was made by, L. G. Mityushin, Problemy Peredachi Informii, 9, 81 (1973).

6. J. B. Keller, J. Chem. Phys., 37, 2584 (1962).

7. L. Lazare, J. Chem. Phys., 38, 727 (1963).

8. M. Ueda, Polym. Prepr., Jpn., 28(6), 1022 (1979). 